\title{
Multicomponent Short-Term Training of ASHAs for Stroke Risk Factor Management in Rural India
}

\author{
Maneeta Jain ${ }^{1} \quad$ Jeyaraj Pandian ${ }^{1} \quad$ Clarence Samuel $^{2}$ \\ Mahesh Kate ${ }^{1}$ \\ 1Department of Neurology, Christian Medical College, Ludhiana, \\ Punjab, India \\ ${ }^{2}$ Department of Community Medicine, Christian Medical College, \\ Ludhiana, Punjab, India
}

Shavinder Singh ${ }^{2}$

Deepshikha Kamra²

Address for correspondence Mahesh Kate, MD, DM, Department of Neurology, Christian Medical College, Brown Road, Ludhiana, Punjab 141008, India (e-mail: maheshpkate@gmail.com).

J Neurosci Rural Pract 2019;10:592-598

\begin{abstract}
Keywords

- stroke

- prevention

- task-shifting

- blood pressure

- ASHA

Background Stroke is one of the leading causes of disability-adjusted life years and may be the leading cause of death in rural regions in India. We aim to train the ASHAs (Accredited Social Health activist) for nonpharmacological management of risk factors for secondary stroke prevention in rural India. We tested the hypothesis that focused, multicomponent, short-term training on secondary prevention of stroke enhances the knowledge of ASHAs about risk factor management.

Objectives To test the hypothesis that focused, multicomponent, short-term training on secondary prevention of stroke enhances the knowledge of ASHAs about risk factor management.

Materials and Methods This study is part of the ASSIST trial (Training ASHA to Assist in Secondary Stroke Prevention in Rural Population). The study design is quasi-experimental (pretest and posttest). Culturally appropriate and pragmatic training material was developed by the study team. Three focused group training sessions were conducted in Sidhwan Bet and Pakhowal blocks of Ludhiana district, Punjab.

Results A total of 274 ASHAs from 164 villages with mean \pm SD age of $39.5 \pm 7$.6 years participated in the three training sessions. The perceived knowledge of stroke risk factors and blood pressure assessment was $67.5 \pm 18.3 \%$ and $84.4 \pm 16.7 \%$, respectively. The objective baseline knowledge about stroke prevention and management among ASHAs was lower $58.7 \pm 19.7 \%$ compared with perceived knowledge $(p=0.04)$. This increased to $82.5 \pm 16.36 \%(p<0.001)$ after the mop-up training after a mean of 191 days. More than $30 \%$ increment was seen in knowledge about the stroke symptoms $(35.9 \%, p<0.001)$, avoiding opium after stroke for treatment $(39.5 \%, p<$ $0.001)$, causes of stroke $(53.3 \%, p<0.001)$, modifiable risk factors for stroke $(45.4 \%$, $p<0.001)$, and lifestyle modifications for stroke prevention $(42.1 \%, p<0.001)$.

Conclusions Focused group training can help enhance the knowledge of ASHAs about stroke prevention and management. ASHAs are also able to retain this complex multicomponent knowledge over a 6 -month period. ASHA may be able to partake in reducing the secondary stroke burden in rural India.
\end{abstract}

\section{Introduction}

Stroke is the one of the leading causes of disability-adjusted life years and may be the leading cause of death in rural regions in India. ${ }^{1,2}$ Furthermore, patients after stroke are at an increased risk of recurrent stroke, coronary artery disease, and mortality. Secondary prevention in stroke patients is primarily done by neurologists in India. Less than $3 \%$ of neurologists live in rural areas covering less than $10 \%$ of the rural population. ${ }^{3}$ There is shortage of permanent primary 
care physicians as well in the rural regions. Hence, secondary stroke prevention is an unmet need.

Secondary prevention after stroke involves the persistent control of risk factors. In patients with minor ischemic stroke receiving dual antiplatelet therapy, high blood pressure (BP) is associated with twofold risk of recurrent stroke. ${ }^{4}$ INTERSTROKE study demonstrated that 10 potentially modifiable risk factors are associated with $90 \%$ of population attributable risk of first ever stroke. Developing strategy to control them is a global priority. ${ }^{5}$ Management of risk factors includes screening, education, treatment, and follow-up. Except pharmacological treatment, all steps can be delegated to nonphysician health workers. ${ }^{6}$ The first step would be to increase the knowledge base of the community health workers (CHWs). ${ }^{7}$ Nurses can assist in control of stable uncontrolled hypertension and noncommunicable disease. ${ }^{8,9}$ However, auxiliary nurse midwife (ANM) in rural India is burdened with multiple tasks, including communicable diseases prevention and treatment as well.

In India, ASHAs (Accredited Social Health activists) are a village-level community health volunteers and social mobilisers. They are female residents of the villages and paid a fee-for-service for certain primary health care services. They are trained to provide a linkage between the health system and the community for maternal and child health care to the rural population. An ASHA may be trained for the nonpharmacological hypertension management. ${ }^{10,11}$

Stroke prevention is multicomponent and encompasses the control of high BP, diabetes, increasing physical activity, augmenting diet with fruits and vegetables, reducing serum cholesterol levels, decreasing the waist-to-hip ratio, reducing psychosocial stress, management of cardiac causes of stroke, and measures to quit smoking and stop alcohol consumption. We aim to train the ASHAs for nonpharmacological management of risk factors for secondary stroke prevention in rural India. We tested the hypothesis that focused, multicomponent, short-term training on secondary prevention of stroke enhances the knowledge of ASHAs about risk factor management.

\section{Materials and Methods}

This study is part of the ASSIST trial (Training ASHA to Assist in Secondary Stroke Prevention in Rural Population, CTRI/2018/09/015709). ASSIST study is a cluster randomized controlled, blinded endpoint trial to reduce BP in patients with stroke. This study design is quasi-experimental (pretest and posttest). The ethics committee of the Christian Medical College and Hospital, Ludhiana, Punjab, India, approved the study.

\section{Study Area and Study Participant}

The study was conducted in Pakhowal and Sidhwan Bet blocks of Ludhiana District of Punjab state in India ( - Fig. 1). The study area has been part of Ludhiana Rural Stroke Registry from 2015 to 2018, which aimed to ascertain the incidence and prevalence of stroke in these regions. The ASHAs in the region were trained to detect stroke patients. In Pakhowal, a total of 140 ASHAs and 25 ANMs cater to 70 villages with a population of 109,201 (Census 2011).

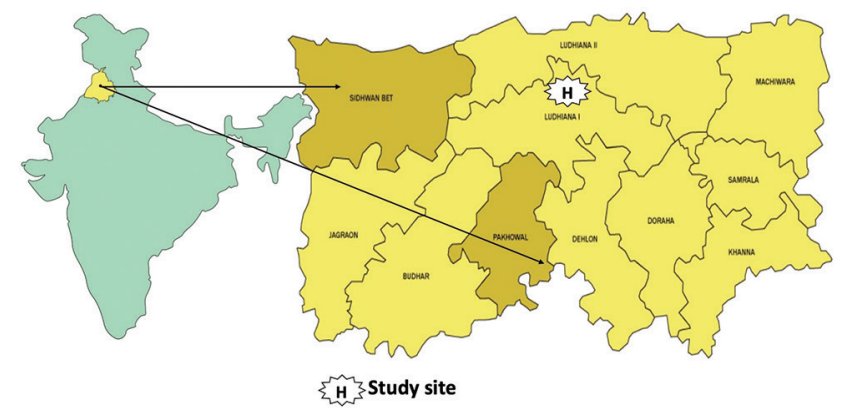

Fig. 1 Study site. The dark colored areas are the blocks where the study was conducted in the Ludhiana district.

There is 1 community health center ( $\mathrm{CHC}$ ), 4 primary health centers (PHCs), and 25 subcenters. In Sidhwan Bet, a total of 120 ASHAs and 25 ANMs cater to 94 villages with a population of 127,065 . There is $1 \mathrm{CHC}, 5 \mathrm{PHCs}$, and 25 subcenters. We included both ASHAs and ANM in the teaching sessions.

\section{Training Material Development}

The training material development team included stroke neurologists (J.P. and M.K.), public health specialists (S.S., C.S., and D.K.), a field expert (M.J.), a Punjabi language expert, and ASHAs from the study area. The categories were decided by the team after reviewing the available literature, including ASHA training module for noncommunicable diseases developed by National Health Mission, India, Patient education material for SPRINT INDIA trial, and patient resources from Heart and Stroke Foundation, Canada. The material was developed keeping local context in mind and based on the Malcolm Shepherd Knowles principles of Andragogy.

\section{Categories}

1. Stroke: types of stroke, symptoms of stroke, early investigation, and management

2. Risk factor of stroke: what is a risk factor, modifiable and non-modifiable risk factors

3. Myths and beliefs: discourage from stopping medications and continue exercise

4. High BP: effects of high BP and measures to control them

5. Exercise to prevent stroke: finding every opportunity to be active

6. Diabetes mellitus or high blood sugar: effects of high blood sugar and measures to control it

7. Dyslipidemia or high cholesterol in blood: relevance of cholesterol in our body and measures to control if it is increased in blood

8. Atrial fibrillation or irregular heart beat: how to detect and reduce the risk of stroke

9. Food for stroke prevention: how to bring about change in diet with practical tips

10. Living after stroke

The workbook consisted of practical tips how to check BP with a digital machine and blood glucose levels with a 
point-of-care device. The workbook chapters were further divided according to the weeks of planned visits for the ASSIST study patients. ${ }^{12}$ Stories were included to highlight the messages in the chapters and initiate conversation with the patients.

\section{Focused Group Training Sessions}

The training sessions were planned to be small focused group (20-25 ASHAs or ANMs allocated to one trainer) so that individual attention could be given. The training team comprises a neurologist (M.K.) and public health experts (S.S., C.S., D.K., and M.J.). The 15- to 18-hour sessions were spread over 3 days given separately to each block. The first two sessions were conducted in the local $\mathrm{CHC}$ and third session was conducted at the subcenter level with 8 to 10 ASHAs in each session.

\section{First Training}

The aim of the first training was sensitization about the risk factors of stroke and hands-on measurement of BP with digital machine. A total of 25 interactive teaching sessions were conducted for four ASHA groups and one ANM group with the help of five trainers, each lasting 30 to 40 minutes. The sessions included understanding the burden of stroke in the district of Ludhiana, India, early/easy identification of stroke symptoms, top-10 risk factors of stroke, measurement of BP and understanding high BP, and effective ways of communication with the stroke patients to adopt healthy lifestyle.

\section{Second Training}

The aim of the second day was revision of stroke risk factors and hands-on training of BP and blood glucose measurement. A total of 20 interactive teaching sessions were conducted for three ASHA and one ANM groups with the help of four trainers, each lasting for 30 to 40 minutes. The sessions included top-10 risk factors of stroke, monitoring of risk factors, hands-on BP measurement and high-BP management (pharmacological and nonpharmacological), and hands-on blood glucose measurement and high-glucose management (pharmacological and nonpharmacological). In each session, emphasis was given on communication with patients and family members. Examples of effective nonthreatening methods to improve compliance and adopt healthy lifestyles were given.

\section{Mop-up Training Session}

ASHAs who could not come to the first and second training sessions were involved in the mop-up training sessions. A total of 14 training sessions ( 2 hours each) were conducted (6 in Pakhowal and 8 in Sidhwan Bet) at the subcenter level. The topics discussed were understanding the top-10 risk factors of stroke, hands-on session on measurement of BP and blood glucose, and how to adopt effective communication strategies while talking to the patients. ASHAs were also provided with the teaching material (a workbook) in Punjabi language at home for revising the topic discussed in the sessions. All ASHAs were given Rs 100 only for attending each day, which covered the travel.

\section{Training Evaluation}

All participating ASHAs completed three questionnaires at the beginning of the first training session. The first questionnaire had a theme of perception of ASHAs aboutBPmeasurementand high-BP (Supplementary Appendix I, available online only). The second questionnaire assessed perception of ASHAs about risk factors of stroke and their control (Supplementary Appendix II, available online only). None of the above questionnaires actually assessed the objective knowledge. Both these instruments were in the form of a forced-choice design (yes/no).

A third objective, self-reported questionnaire about stroke risk factor monitoring and management was used for pre- and posttraining assessment (Supplementary Appendix III, available online only). The tool was of multiple-choice pattern with a single or multiple correct option from four similar distractor options. The stem and options of the questionnaire were designed for grade 4 level reading. The ASHAs were given instructions regarding the test instrument and 20 minutes were given to complete the test. The test was repeated at the end of second training or during the mop-up training sessions.

\section{Statistical Analysis}

Demographic characteristics of ASHAs were reported as medians and ranges. Quantitative data on knowledge about stroke were assessed using two-tailed paired $t$-tests for comparing scores within groups (SPSS version 20 for windows). The McNemar test was used to compare the individual question response of pretraining with the follow-up training 1 and 2. The ANOVA with repeated measures after the Bonferroni adjustments was performed to evaluate the effect of two follow-up training sessions. The comparison among ANMs and ASHAs was done using independent $t$-test.

\section{Results}

A total of 274 ASHAs from 164 villages participated in the training program in both the blocks. The mean \pm SD age of ASHAs and ANMs, respectively, was $39.5 \pm 7.6$ years and $40.1 \pm 7.1$ years, respectively. The mean duration of education was 8.6 \pm 3.1 years for ASHAs and $12.89 \pm 0.75$ years for ANMs. The mean work experience of ASHAs in service was $7.4 \pm 3.2$ years and $14.30 \pm 7.7$ years for ANMs. During the training period, 14 ASHAs left the job, which were replaced by the 14 new ASHAs, and 3 ANMs retired and were replaced by new ones. All the new ASHAs and ANMs received at least one training session. Seventy-eight percent (214/274) ASHAs and 53\% (28/53) ANMs participated in two or more training sessions.

\section{Pretraining}

During the first training, the participating ASHAs (213) and 47 ANMs were assessed for their perceived knowledge about stroke risk factor control and BP (-Tables 1 and 2). ASHAs perceived that they knew about stroke risk factor control in both the Sidhwan Bet and Pakhowal blocks. More than threefourths of the ASHAs felt that they were aware about the 
Table 1 Perception of knowledge of stroke risk factors prior to training

\begin{tabular}{|c|c|c|c|}
\hline Questions & Pakhowal, $n(\%)(n=112)$ & $\begin{array}{l}\text { Sidhwan Bet, } n(\%) \\
(n=101)\end{array}$ & $\begin{array}{l}\text { Total, } n(\%) \\
(n=213)\end{array}$ \\
\hline Know how to measure blood pressure & $107(95.5)$ & $100(99.0)$ & $207(97.2)$ \\
\hline Know how to measure blood sugar & $71(63.4)$ & $88(87.1)$ & 159 (74.6) \\
\hline Know how long to exercise for stroke prevention & $64(57.1)$ & $71(76.2)$ & $135(63.4)$ \\
\hline Know what to eat for stroke prevention & $88(78.6)$ & $68(67.3)$ & $156(73.2)$ \\
\hline Know about atrial fibrillation & $36(32.1)$ & $41(40.6)$ & $77(36.2)$ \\
\hline Know how to reduce alcohol intake & $82(73.2)$ & $82(81.2)$ & $164(76.9)$ \\
\hline Know how to quit smoking & $54(48.2)$ & $63(62.4)$ & $117(54.9)$ \\
\hline Know to reduce weight in an obese patient & $102(91.1)$ & $93(92.1)$ & $195(91.5)$ \\
\hline Know how to measure body fat & $65(58.0)$ & $68(67.3)$ & $95(44.6)$ \\
\hline Know how to reduce stress & $32(28.6)$ & $63(62.4)$ & $133(62.4)$ \\
\hline
\end{tabular}

Table 2 Perception of knowledge about blood pressure assessment prior to training

\begin{tabular}{|c|c|c|c|}
\hline Questions & $\begin{array}{l}\text { Pakhowal, } n(\%) \\
(n=112)\end{array}$ & $\begin{array}{l}\text { Sidhwan Bet, } n(\%) \\
(n=101)\end{array}$ & $\begin{array}{l}\text { Total, } n(\%) \\
(n=213)\end{array}$ \\
\hline Have you received training to measure blood pressure? & $95(84.8)$ & $95(94.1)$ & $190(89.2)$ \\
\hline $\begin{array}{l}\text { Know how long to wait and to be relaxed posture prior to BP } \\
\text { measurement }\end{array}$ & $109(97.3)$ & $100(99.0)$ & $209(98.1)$ \\
\hline Know BP has two values, upper and lower & $109(97.3)$ & $91(90.1)$ & $194(91.1)$ \\
\hline Know normal systolic BP value & $107(95.5)$ & $94(93.1)$ & $201(94.4)$ \\
\hline Know normal diastolic BP value & $111(99.1)$ & $94(93.1)$ & $205(96.2)$ \\
\hline Know when to label a person hypertensive & $99(88.4)$ & $91(90.1)$ & $190(89.2)$ \\
\hline Know when to label a person hypotensive & $99(88.4)$ & $88(87.1)$ & $187(87.2)$ \\
\hline $\begin{array}{l}\text { Know how many times BP should be measured before labeling person } \\
\text { hypertensive }\end{array}$ & $84(75.0)$ & $80(79.2)$ & $164(76.9)$ \\
\hline Know how to control hypertension & $99(88.4)$ & $80(79.2)$ & $179(84.0)$ \\
\hline Know side effects of antihypertensive medications & $39(34.8)$ & $41(40.6)$ & $80(37.5)$ \\
\hline
\end{tabular}

Abbreviation: BP, blood pressure.

top-10 stroke risk factors (mean of $67.5 \pm 18.3 \%$ ) except about atrial fibrillation and measurement of waist-to-hip ratio. Almost 90\% ASHAs felt that they knew BP measurement and hypertension management (mean of $84.4 \pm 16.7 \%$ ) except side effects of antihypertensive medications. In the objective multiple-choice questionnaire, the average knowledge score of all ASHAs at baseline was $58.7 \pm 19.7 \%$ (63.4 $\pm 18.1 \%$ in Sidhwan Bet and $54.4 \pm 18.3 \%$ in Pakhowal, $p=0.94$ ). The objective baseline knowledge about stroke prevention and management was lower compared with the perceived knowledge $(p=0.04)$.

\section{Posttraining}

The time gap between first and second training sessions was 69 days for Sidhwan Bet and 75 days for Pakhowal. The time gap between second training and mop-up training was 129 days for Sidhwan Bet and 112 days for Pakhowal. The mean overall knowledge score in the objective multiple-choice questionnaire increased to $82.5 \pm 16.4 \%$ after the mop-up training $\left(t_{151}=-14.4, p \leq 0.001\right)$. Both the sites showed a statistically significant increase with $49 \pm 18.06 \%(p \leq 0.001)$ at Pakhowal and 32 $\pm 16.25 \%$ ( $p \leq 0.001$ ) at Sidhwan Bet in the mop-up (third) posttraining assessment compared with the pretraining. However, there was no difference between the two areas ( $p=0.346)$. The knowledge about the normal BP and normal blood glucose remained $100 \%$ throughout the training sessions (- Table 3 ). The knowledge about the medicine that helps in stroke prevention has increased from 37 to $59 \%$. Medical condition as risk factors knowledge was $99 \%$ in posttraining (- Table 4).

A total of 274 ASHAs were trained to measure BP with digital BP machine. They were trained to take three readings in nonparetic upper arm with appropriate positioning of the BP cuff. The ASHAs checked BP on two separate occasions to the satisfaction of the field trainers. A total of 274 ASHAs were trained to measure blood glucose with point-of-care device. They were trained to maintain aseptic condition prior to finger-prick. There were able to appropriately place the drop of blood on the sensor zone. The ASHAs checked blood glucose on two separate occasions to the satisfaction of the field trainers. All the ASHAs were also made aware of the ASSIST study protocol. Activities to be conducted during each visit. A total of 274 ASHAs were trained to make video call to the study doctor on the WhatsApp messaging mobile application.

More than $30 \%$ increment was seen in knowledge about the stroke symptoms $(35.9 \%, p<0.001)$, avoiding opium 
Table 3 Correct responses by the ASHAs to the individual objective multiple choice questions

\begin{tabular}{|c|c|c|c|c|c|c|c|}
\hline \multirow{2}{*}{\multicolumn{2}{|c|}{ Questions }} & \multicolumn{3}{|c|}{ Pakhowal } & \multicolumn{3}{|c|}{ Sidhwan Bet } \\
\hline & & $\begin{array}{l}\text { Pretraining } \\
(n=112)(\%)\end{array}$ & $\begin{array}{c}\text { Second training } \\
(n=80)(\%)\end{array}$ & $\begin{array}{l}\text { Mop-up training } \\
(n=114)(\%)\end{array}$ & $\begin{array}{l}\text { Pretraining } \\
(n=101)(\%)\end{array}$ & $\begin{array}{l}\text { Second training } \\
(n=99)(\%)\end{array}$ & $\begin{array}{c}\text { Mop-up training } \\
(n=86)(\%)\end{array}$ \\
\hline 1 & Stroke symptoms & $32(28.6)$ & $41(51.3)$ & $78(68.4)$ & $45(44.6)$ & $75(75.8)$ & $68(79.1)$ \\
\hline 2 & Stroke treatment & $81(72.3)$ & $58(72.5)$ & $94(82.5)$ & $72(71.3)$ & $51(51.5)$ & $70(81.4)$ \\
\hline 3 & $\begin{array}{l}\text { Stroke preven- } \\
\text { tion- medication }\end{array}$ & $42(37.5)$ & $42(52.5)$ & $63(55.3)$ & $26(25.7)$ & $61(61.6)$ & $56(65.1)$ \\
\hline 4 & $\begin{array}{l}\text { Stroke preven- } \\
\text { tion-lifestyle }\end{array}$ & $23(20.5)$ & $45(56.3)$ & $80(70.2)$ & $38(37.6)$ & $75(75.8)$ & $63(73.3)$ \\
\hline 5 & $\begin{array}{l}\text { Risk factors for } \\
\text { stroke }\end{array}$ & $31(27.7)$ & $45(56.3)$ & $72(63.2)$ & $48(47.5)$ & $63(63.6)$ & $57(66.3)$ \\
\hline 6 & $\begin{array}{l}\text { Normal blood } \\
\text { pressure }\end{array}$ & $112(100)$ & $80(100)$ & $114(100)$ & $101(100)$ & $99(100)$ & $86(100)$ \\
\hline 7 & $\begin{array}{l}\text { Normal blood } \\
\text { glucose }\end{array}$ & $112(100)$ & $80(100)$ & $114(100)$ & $101(100)$ & $99(100)$ & $86(100)$ \\
\hline 8 & Opium in stroke & $57(50.9)$ & $74(92.5)$ & $111(97.4)$ & $61(60.4)$ & $84(84.8)$ & $81(94.2)$ \\
\hline 9 & Brain control & $37(33.0)$ & $15(18.8)$ & $69(60.5)$ & $52(51.5)$ & $32(32.3)$ & $50(58.1)$ \\
\hline 10 & Types of stroke & $57(50.9)$ & $62(77.5)$ & $87(76.3)$ & $52(51.5)$ & $80(80.8)$ & $71(82.6)$ \\
\hline 11 & $\begin{array}{l}\text { Modifiable risk } \\
\text { factors }\end{array}$ & $29(25.9)$ & $31(38.8)$ & $86(75.4)$ & $34(33.7)$ & $66(66.7)$ & $62(72.1)$ \\
\hline 12 & $\begin{array}{l}\text { Medical con- } \\
\text { ditions as risk } \\
\text { factors }\end{array}$ & $37(33.0)$ & $72(90.0)$ & $96(84.2)$ & $45(44.6)$ & 92 (92.9) & 79 (91.9) \\
\hline 13 & $\begin{array}{l}\text { Diagnostic test } \\
\text { for stroke }\end{array}$ & $63(56.3)$ & $61(76.3)$ & $103(90.4)$ & $90(89.1)$ & $82(82.8)$ & $83(96.5)$ \\
\hline 14 & $\begin{array}{l}\text { Golden time } \\
\text { period for stroke } \\
\text { treatment }\end{array}$ & $98(87.5)$ & $76(95.0)$ & 113 (99.1) & $96(95.0)$ & $97(98.0)$ & $86(100.0)$ \\
\hline 15 & $\begin{array}{l}\text { Improving good } \\
\text { cholesterol }\end{array}$ & $103(92.0)$ & $79(98.8)$ & $113(99.1)$ & $100(99.0)$ & 93 (93.9) & $83(96.5)$ \\
\hline
\end{tabular}

Table 4 Effect of the training program on the ASHAs' knowledge about stroke

\begin{tabular}{|c|c|c|c|c|c|c|}
\hline Variables & $\begin{array}{l}\text { Pretraining, } \\
n(\%)\end{array}$ & $\begin{array}{l}\text { Second } \\
\text { training, } n(\%)\end{array}$ & $p$-Value & Pretraining, $n$ (\%) & $\begin{array}{l}\text { Mop-up } \\
\text { training, } n(\%)\end{array}$ & $p$-Value \\
\hline Stroke symptoms & $53(39.6)$ & $85(63.4)$ & $<0.001$ & $54(35.5)$ & $107(70.4)$ & $<0.001$ \\
\hline Stroke treatment & $91(67.9)$ & $85(63.4)$ & 0.12 & $105(69.1)$ & $129(84.9)$ & 0.12 \\
\hline $\begin{array}{l}\text { Stroke } \\
\text { prevention-medication }\end{array}$ & $44(32.8)$ & $78(58.2)$ & $<0.001$ & $51(33.6)$ & $85(55.9)$ & $<0.001$ \\
\hline $\begin{array}{l}\text { Stroke } \\
\text { prevention-lifestyle }\end{array}$ & $40(29.9)$ & $90(67.2)$ & $<0.001$ & $41(27.0)$ & $105(69.1)$ & $<0.001$ \\
\hline Risk factors for stroke & $56(41.8)$ & $79(59.0)$ & $<0.001$ & $57(37.5)$ & $91(59.9)$ & $<0.001$ \\
\hline Opium in stroke & $77(57.5)$ & $124(92.5)$ & $<0.001$ & $87(57.2)$ & $147(96.7)$ & $<0.001$ \\
\hline Brain control & $59(44.0)$ & $35(26.1)$ & 0.001 & $64(42.1)$ & $90(59.2)$ & 0.003 \\
\hline Types of stroke & $68(50.7)$ & $111(82.8)$ & $<0.001$ & $76(50)$ & $119(78.3)$ & $<0.001$ \\
\hline Modifiable risk factors & $40(29.9)$ & $71(53.0)$ & $<0.001$ & $44(28.9)$ & $113(74.3)$ & $<0.001$ \\
\hline $\begin{array}{l}\text { Medical conditions as } \\
\text { risk factors }\end{array}$ & $57(42.5)$ & $131(97.8)$ & $<0.001$ & $57(37.5)$ & $138(90.8)$ & $<0.001$ \\
\hline $\begin{array}{l}\text { Diagnostic test for } \\
\text { stroke }\end{array}$ & $99(73.9)$ & $110(82.1)$ & 0.13 & $106(69.7)$ & $141(92.8)$ & $<0.001$ \\
\hline $\begin{array}{l}\text { Golden time period for } \\
\text { stroke treatment }\end{array}$ & $122(91.0)$ & $127(94.8)$ & 0.03 & $138(90.8)$ & $151(99.3)$ & $<0.001$ \\
\hline $\begin{array}{l}\text { Improving good } \\
\text { cholesterol }\end{array}$ & $128(96.2)$ & $129(97.0)$ & 1 & $143(94.1)$ & $148(97.4)$ & 0.3 \\
\hline
\end{tabular}


after stroke for treatment $(39.5 \%, p<0.001)$, causes of stroke $(53.3 \%, p<0.001)$, modifiable risk factors for stroke $(45.4 \%, p<0.001)$, and lifestyle modifications for stroke prevention $(42.1 \%, p<0.001)$.

\section{ANM and ASHA Comparison}

A total of 53 ANMs were trained. The perceived knowledge of ASHAs about stroke risk factors and BP assessment was $67.5 \pm 22.5 \%$ and $84.5 \pm 16.2 \%$, respectively, and in ANMs were $51.7 \pm 19.1 \%$ and $82.5 \pm 13.6 \%$, respectively. ASHAs' perceptions about stroke risk factors were more than the ANMs' and statistically significant $(p<0.001)$ and no difference in perception about BP assessment between the two groups. The average score on the objective questionnaire of ANMs during pretraining was $78.01 \pm 15 \%$ and it improved to $89.8 \pm 10.1 \%$ after second training $(p=0.001)$. The ANMs performed better than the ASHAs during pre training $(p<0.001)$ and also during follow-up training $(p=0.015)$.

\section{Discussion}

In this focused training study, there was incremental enhancement and retention of knowledge of ASHAs regarding stroke treatment and prevention over a period of 6 months. The ASHAs additionally were trained for measurement of BP on digital machine and measurement of blood glucose on point-of-care device. Furthermore, they were trained to do video and audio phone call on WhatsApp messaging mobile application.

In an observational study, CHWs were able to accurately screen for cardiovascular disease risk and also allocate risk score in comparison to the health care professionals (mean level of agreement $96.8 \%$ ). ${ }^{15}$ The training was done over a period of 1 to 2 weeks. A total of 68 CHWs were trained and 42 scored $>60 \%$ qualified for the community screening. They were trained to measure BP and body mass index. In another study, 15 ASHAs from South India were trained for delivering community health education, measuring BP and weight for hypertension management. The baseline knowledge of the ASHA in that study improved from 64 to $76 \%$ after training and to $84 \%$ after 3 months' intervention. ${ }^{11}$ In our study, the baseline objective knowledge for stroke prevention and treatment also improved from 58.7 to $82.5 \%$ after mop-up training at 6 months.

Culturally appropriate and pragmatic training of CHWs is the first step for effective task shifting and task-sharing strategies. In the SimCard trial, CHWs were effectively able to deliver a simplified cardiovascular management program with the aid of smartphone-based electronic support system. ${ }^{16}$ The antihypertensive medication use in villages in both India and China increased by $25.5 \%$. The DISHA study is currently assessing the role of frontline CHWs, including ASHAs and Anganwadi workers for delivering structured multicomponent intervention for cardiovascular risk reduction. ${ }^{10}$ The $\mathrm{CHWs}$ received a training for
2 days on CVD risk factors, how to prevent progression of risk factors, lifestyle interventions, and intervention package. The CHWs will undertake nine visits over an 18-month period. This is a primary prevention study and the aim is $\mathrm{BP}$ reduction. In secondary prevention for coronary artery disease trial, a recent study showed significant uptake of healthy lifestyle (regular physical activity $+29 \%$, odds ratio $[\mathrm{OR}]=5.2, p<0.001)$ and evidence-based medications $(+5 \%$, OR 2.62, $p=0.006)$ when CHWs were involved early. ${ }^{17}$ The CHWs used unstructured discussion, visual methods, and patients' diaries for a total of six visits. A similar ongoing study (CTRI/2015/12/006424) in rural Gadchiroli district of Maharashtra, India, is trying to reduce the primary stroke mortality with the help of village-based CHWs and outreach physicians. CHWs are targeting reduction of salt intake, tobacco, and alcohol use. The outreach physician targets hypertension, diabetes, and secondary stroke prevention. The results of this study are early awaited. Thus, ASHAs may be able to assist in task-shifting across the entire spectrum of NCD care pathway, primordial, primary, secondary, and tertiary prevention.

ASHA program was launched in 2005 with the aim of improving maternal and child care. It has become largest all-female CHW program in the world with almost one million ASHAs. The ASHA program is further strengthened by the ASHA empowerment initiatives of government. ${ }^{18}$ Being from the same village and motivated, she has direct access to most households and members. ${ }^{19}$ As the ASHAs are monitored and supported by the ANMs, sensitizing the ANMs about prevention strategy of NCDs can help them guide the ASHAs to meet the unmet need for NCDs prevention in the rural community efficiently. ${ }^{20}$ Although the ANMs performed better than the ASHAs in both the phases of the training, but after the posttraining the difference is small. Despite wide difference in the education and training of ANMs and ASHAs, the study shows that ASHAs can be trained to deliver certain health care facilities. This may allow better screening, treatment, and follow-up monitoring of high-priority disease conditions with a stable course. The enhancement, retention, and efficacy of knowledge of the ASHAs can be further bolstered with the use of smartphone and mobile applications. ${ }^{21}$

\section{Strengths and Limitations}

The training material was developed after involvement of all community stakeholders. We took into consideration the multitheories model of medical. Thus, we initially tested the perception of ASHA about the topics of training to challenge existing concepts (dissonance phase).22 The focused group training helped us refine, organize, and consolidate the knowledge and also get appropriate feedback. We are able to give at least one training to all the ASHAs in the respective blocks. All the ASHAs were not able to attend all the training sessions because of several reasons; transportation to the training venue ( $\mathrm{CHC}$ of the block) was the main reason. 


\section{Conclusion}

Focused group training can help enhance the knowledge of ASHAs about stroke prevention and management. ASHAs are also able to retain this complex multicomponent knowledge over a 6-month period. ASHA may be able to partake in reducing the secondary stroke burden in rural India.

\section{Funding}

The study was funded by the World Federation of Neurology Grant 2016 LOI and Indian Council of Medical Research, India.

\section{Conflict of Interest}

None declared.

\section{Acknowledgment}

Ms Sunita, Mr Amritpal Singh, Ms Rajni Malik, and Mr Mohit Kumar were the field research coordinators from Department of Community Medicine for the study.

\section{References}

1 Dandona L, Dandona R, Kumar GA, et al; India State-Level Disease Burden Initiative Collaborators. Nations within a nation: variations in epidemiological transition across the states of India, 1990-2016 in the Global Burden of Disease Study. Lancet 2017;390(10111):2437-2460

2 Kalkonde YV, Deshmukh MD, Sahane V, et al. Stroke is the leading cause of death in rural Gadchiroli, India: a prospective community-based study. Stroke 2015;46(7):1764-1768

3 Ganapathy K. Distribution of neurologists and neurosurgeons in India and its relevance to the adoption of telemedicine. Neurol India 2015;63(2):142-154

4 Wangqin R, Wang X, Wang Y, et al. Risk factors associated with 90-day recurrent stroke in patients on dual antiplatelet therapy for minor stroke or high-risk TIA: a subgroup analysis of the CHANCE trial. Stroke Vasc Neurol 2017;2(4):176-183

5 O'Donnell MJ, Chin SL, Rangarajan S, et al; INTERSTROKE Investigators. Global and regional effects of potentially modifiable risk factors associated with acute stroke in 32 countries (INTERSTROKE): a case-control study. Lancet 2016;388(10046):761-775

6 Ajay VS, Tian M, Chen H, et al. A cluster-randomized controlled trial to evaluate the effects of a simplified cardiovascular management program in Tibet, China and Haryana, India: study design and rationale. BMC Public Health 2014;14:924

7 Akinyemi RO, Owolabi MO, Adebayo PB, et al. Task-shifting training improves stroke knowledge among Nigerian non-neurologist health workers. J Neurol Sci 2015;359(1/2):112-116

8 Some D, Edwards JK, Reid T, et al. Task shifting the management of non-communicable diseases to nurses in Kibera, Kenya: does it work? PLoS One 2016;11(1):e0145634

9 Gyamfi J, Iwelunmor J, Blackstone SR, et al. Training nurses in task-shifting strategies for the management and control of hypertension in Ghana: a mixed-methods study. BMC Health Serv Res 2017;17(1):1-9

10 Jeemon P, Narayanan G, Kondal D, et al; DISHA Study Investigators. Task shifting of frontline community health workers for cardiovascular risk reduction: design and rationale of a cluster randomised controlled trial (DISHA study) in India. BMC Public Health 2016;16(1):264

11 Abdel-All M, Thrift AG, Riddell M, et al. Evaluation of a training program of hypertension for accredited social health activists (ASHA) in rural India. BMC Health Serv Res 2018;18(1):320

12 Kate M, Pandian JD, Singh S, Jain M, Samuel C, Kamra D. Aarogya Sahayak (the Healer). figshare. [Book]; 2019. Available at: https://doi.org/10.6084/m9.figshare.10321244.v1

13 Pandian JD, Gall SL, Kate MP, et al. Prevention of stroke: a global perspective. Lancet 2018;392(10154):1269-1278

14 Arora D, Kate M, Verma SJ, et al. Secondary prevention by structured semi-interactive stroke prevention package in India (sprint India) study: formative, acceptability and implementation stages of the study. Int J Stroke 2018;13:100-100

15 Gaziano TA, Abrahams-Gessel S, Denman CA, et al. An assessment of community health workers' ability to screen for cardiovascular disease risk with a simple, non-invasive risk assessment instrument in Bangladesh, Guatemala, Mexico, and South Africa: an observational study. Lancet Glob Health 2015;3(9):e556-e563

16 Tian M, Ajay VS, Dunzhu D, et al. A cluster-randomized, controlled trial of a simplified multifaceted management program for individuals at high cardiovascular risk (SimCard Trial) in Rural Tibet, China, and Haryana, India. Circulation 2015;132(9):815-824

17 Xavier D, Gupta R, Kamath D, et al. Community health worker-based intervention for adherence to drugs and lifestyle change after acute coronary syndrome: a multicentre, open, randomised controlled trial. Lancet Diabetes Endocrinol 2016;4(3):244-253

18 Ved R, Scott K, Gupta G, et al. How are gender inequalities facing India's one million ASHAs being addressed? Policy origins and adaptations for the world's largest all-female community health worker programme. Hum Resour Health 2019;17(1):3

19 Gopalan SS, Mohanty S, Das A. Assessing community health workers' performance motivation: a mixed-methods approach on India's Accredited Social Health Activists (ASHA) programme. BMJ Open 2012;2(5):e001557

20 Kerry Scott, Dena Javadi, and Jessica Gergen (comments from Dr. Rajani Ved and contributions from Rachel Strodel. India's Auxiliary Nurse-Midwife, Anganwadi Worker, Accredited Social Health Activist, Multipurpose Worker, and Lady Health Visitor Programs

21 Shah S, Shinde A, Anand A, et al. The role of an mHealth intervention in improving knowledge and skills of accredited social health activists in tribal areas of Gujarat, India: a nested study within an implementation research trial. Acta Paediatr 2018;107(suppl 471):72-79

22 Taylor DCM, Hamdy H. Adult learning theories: implications for learning and teaching in medical education: AMEE Guide No. 83. Med Teach 2013;35(11):e1561-e1572 